\title{
DIGNIDADE SEXUAL E PROTEÇÃO NO SISTEMA PENAL
}

\section{SEXUAL DIGNITY $\mid$ AND PROTECTION CRIMINAL SYSTEM $\square$}

\author{
José Henrique Rodrigues Torres *
}

Torres JHR. Dignidade sexual e proteção no sistema penal. Rev. Bras. Cresc. e Desenv. Hum. 2011; 21(2): 7-10

De nada adiantou Hércules libertar Prometeu dos rochedos que o aprisionavam, pois o miserável Titã continuou a eles acorrentado, eternamente, por um anel feito com uma pedra deles extraída. Com relação ao tratamento legislativo dado à sexualidade, especialmente no âmbito do direito penal, o sistema jurídico brasileiro sofreu, recentemente, profundas mudanças, mas, de nada adiantará a edição de novos e inovadores dispositivos legais se, ao aplicá-los, os seus intérpretes continuarem acorrentados aos paradigmas que estruturavam os rochedos da antiga sistemática jurídica, construída no terreno pantanoso e traiçoeiro da ideologia patriarcal. Como diria Alberto Caeiros, heterônimo de Fernando Pessoa, não basta abrir a janela para ver os campos e os rios. É preciso romper com os antigos paradigmas.

Até 2005, o nosso sistema jurídico-penal, a pretexto de dar proteção à sexualidade, especialmente das mulheres, mantinha, em vários dispositivos incriminadores, a expressão mulher honesta, cunhada, à evidência, por uma ideologia embasada nos paradigmas da dominação masculina, em concepções morais ultrapassadas, na submissão carnal e na subordinação entre os sexos ${ }^{1}$.

Assim, até a edição da Lei n. 11.106/ 2005, para que alguém fosse condenado pelo crime de rapto (Código Penal, artigo 219. Raptar mulher honesta, mediante violência, grave ameaça ou fraude, para fim libidinoso: Penareclusão, de dois a quatro anos), mesmo havendo violência ou grave ameaça, era preciso demonstrar que a mulher raptada era honesta.

E o conceito de honestidade da mulher era determinado, exclusivamente, por padrões androcêntricos, que estabeleciam rigoroso controle sobre a expressão da sexualidade feminina. Além disso, sempre estaria caracterizado o crime de rapto se a mulher contasse menos de vinte e um anos de idade, ainda que houvesse o consentimento da raptada (Código Penal, artigo 220. Se a raptada é maior de catorze anos e menor de vinte e um e o rapto se dá com o seu consentimento: pena de detenção, de um a três anos). Como se vê, a criminalização dessa conduta não tinha o objetivo de proteger as mulheres, mas, sim, de sujeitá-las ao controle absoluto de sua sexualidade até os vinte e um anos de idade.

Além disso, como consagração da ideologia patriarcal no âmbito do sistema penal brasileiro, a virgindade da mulher era considerada como um bem ou um valor, que, na sua dimensão jurídica e social, era merecedor de proteção, como ocorria na criminalização da sedução (Código Penal, artigo 217. Seduzir mulher virgem, menor de dezoito anos e maior de catorze, e ter com ela conjunção carnal, aproveitando-se de sua inexperiência ou justificável confiança: Pena de reclusão, de dois a quatro anos). E, obviamente, a previsão desse crime não visava à proteção das mulheres, como enganadamente era * Juiz de Direito Titular da Primeira Vara Criminal de Campinas. Professor Titular de Direito Penal da Pontifícia Universidade
Católica de Campinas - PUCCamp. 
afirmado. Tratava-se, na realidade, de uma verdadeira capitis de minucia para elas ${ }^{1 .}$

Todavia, apesar da extinção desses dispositivos androcêntricos, revogados apenas em 2005 , o sistema penal brasileiro continuou convivendo com a ultrapassada concepção de que a sexualidade deveria ser controlada por uma pauta moral de comportamento, segundo padrões ditados pela ideologia patriarcal. Assim, os delitos contra a liberdade sexual continuaram inseridos no capítulo dos crimes contra os costumes $^{1}$. E foi somente no final da primeira década do século XXI, com a aprovação da Lei n. 12.015 , de 7 de agosto de 2009, que a sexualidade foi reconhecida como um atributo da pessoa humana e como uma expressão de sua dignidade: essa lei abandonou a antiga e patriarcal concepção de crimes contra os costumes e passou a cuidar da proteção da sexualidade no âmbito da dignidade sexual.

Portanto, o estupro (Código Penal, artigo 213. Constranger alguém, mediante violência ou grave ameaça, a ter conjunção carnal ou a praticar ou permitir que com ele se pratique outro ato libidinoso: Pena - reclusão, de seis a dez anos), o assédio sexual (Código Penal, artigo 216-A. Constranger alguém com o intuito de obter vantagem ou favorecimento sexual, prevalecendose o agente da sua condição de superior hierárquico ou ascendência inerentes ao exercício de emprego, cargo ou função: Pena - detenção, de um a dois anos), o estupro de vulnerável (Código Penal, artigo 217-A. Ter conjunção carnal ou praticar outro ato libidinoso com menor de 14 (catorze) anos: Pena - reclusão de 8 a 15 anos), o favorecimento da prostituição (Código Penal, artigo 228. Induzir ou atrair alguém à prostituição ou outra forma de exploração sexual, facilitála, impedir ou dificultar que alguém a abandone: pena - reclusão, de dois a cinco anos) e outros delitos contra o exercício da sexualidade passaram a ser considerados crimes contra a dignidade sexual ${ }^{2}$.

Além disso, outras alterações legislativas no sistema penal foram aprovadas em 2009 com o objetivo de afastar aquela indesejável concepção patriarcal de sexualidade. Lembre-se, por exemplo, de que, para consagrar o princípio constitucional da igualdade entre homens e mulheres, corolário da dignidade humana, eliminou-se do crime de estupro a referência à mulher como vítima exclusiva desse delito.

Mas, não se olvide que, desde a promulgação da Constituição de 1988, a dignidade humana já era reconhecida pela sociedade brasileira como um princípio fundamental e norteador de todo o sistema jurídico, político e social do nosso país. E a sexualidade, como atributo da pessoa humana, já deveria ter sido, desde então, submetida à proteção no âmbito da dignidade humana. Além disso, é preciso lembrar, também, que o Brasil, em face de suas normas e princípios constitucionais, submetese, também, às normas e princípios de Direitos Humanos, ou seja, de um sistema internacional de proteção do ser humano, especialmente dos mais débeis e fragilizados.

Assim, cabia ao Brasil adaptar a sua legislação e as suas políticas públicas a esses princípios. Aliás, não se olvide que, na Conferência do Cairo (1994), ficou afirmado o compromisso do sistema de Direitos Humanos com a necessidade do abandono da concepção patriarcal de controle da sexualidade das mulheres ${ }^{3}$. E, na Conferência de Beijing (1995), foram expressamente reconhecidos os Direitos Sexuais e Reprodutivos e enfatizada a necessidade da garantia da autodeterminação, da igualdade e da segurança sexual e reprodutiva das mulheres para a plena vivência de sua saúde sexual e reprodutiva, estabelecendo-se que os Estados-Partes, como o Brasil, têm o dever de proteger tais direitos ${ }^{4}$.

Assim, a dignidade sexual, como um valor fundamental, há muito tempo já deveria ter merecido uma adequada proteção do sistema legal brasileiro. Demorou muito tempo para que o legislador, atuando no âmbito abstrato e formal das leis, promovesse a eliminação ou a modificação daqueles dispositivos penais forjados em 
uma concepção machista, preconceituosa e discriminatória da sexualidade.

Contudo, apesar desse avanço legislativo, outro desafio há de ser enfrentado, em especial pelos juízes, responsáveis pela aplicação jurídica desses novos e inovadores dispositivos legais, mas, também, por todos os órgãos responsáveis pela efetivação material de políticas públicas que devem ser construídas e implantadas para garantir a indenidade da dignidade sexual, especialmente das mulheres. É o que evidencia o artigo Influência do exame médico-legal na responsabilização do autor da violência sexual contra adolescentes ${ }^{5}$.

Com efeito, como lembrado nesse estudo, a violência sexual é uma das mais antigas expressões da violência de gênero e uma brutal violação de direitos humanos, de direitos sexuais e de direitos reprodutivos. E, embora comprometa pessoas de ambos os sexos e em qualquer idade, as evidências apontam que o fenômeno declina contundentemente sobre as mulheres, particularmente as mais jovens e vulneráveis ${ }^{5}$. Daí a necessidade da efetiva aplicação dos dispositivos legais disponíveis, bem como de recursos materiais, técnicos e científi$\cos$, para garantir uma maior proteção à dignidade sexual, especialmente dessas mulheres mais jovens e vulneráveis.

Mas, como também evidencia o estudo em referência, embora o sistema judiciário entenda que é imprescindível e decisiva a realização do exame médico-legal para a comprovação material da autoria dos crimes sexuais e, conseqüentemente, para a responsabilização de seus autores, os exames e testes científicos existentes, que poderiam ser utilizados para a complementação e precisão dessa prova, nem sempre estão disponíveis ou são rotineiramente aplicados durante exame médico-legal, particularmente nos países em desenvolvimento ${ }^{5}$. Aliás, a realização desses exames também é importante para garantir a saúde das mulheres ${ }^{6}$.

Além disso, não se pode olvidar, como também demonstra o referido estudo, desbancando mitos, que é baixa a freqüência de uso de violência física na prática dos crimes sexuais. Com efeito, de acordo com a sua definição típica, esses delitos podem e são muita vez praticados mediante ameaça ou até mediante o uso de fraude ou abuso da relação parental $^{2}$. Mas, como verificado, em nosso meio se constata que muitos crimes sexuais contra adolescentes não são submetidos a julgamento por falta de provas materiais, apesar da existência de técnicas bastante precisas para demonstrar a ocorrência do contato sexual.

Finalmente, demonstrando a influência decisiva da concepção patriarcal no sistema judiciário, os autores do referido estudo verificam que o conceito e a dinâmica da violência sexual intrafamiliar ainda não estão devidamente incorporados pelos operadores do direito, $\mathrm{o}$ que pode influenciar negativamente sua convicção sobre a veracidade dos fatos relatados pela vítima. Assim, em face de todos os resultados do estudo realizado, concluem que, embora tenham sido verificados "avanços importantes para a redução da impunidade nos crimes sexuais contra a adolescente", ainda permanece sem resposta a injustificada absolvição de $16,7 \%$ dos acusados, mesmo com exame médico-legal positivo e concordante com o crime sexual alegado pela adolescente . $^{5}$.

Como se vê, para a efetiva garantia da sexualidade como um atributo da dignidade humana, especialmente no âmbito do sistema penal, resta ainda o enfrentamento da ideologia patriarcal, que continua sendo um grande obstáculo para a efetivação da desejada e necessária proteção de um valor jurídico que, segundo a Constituição Federal de 1988, bem como de acordo com a principiologia dos Direitos Humanos, tem importância fundamental para a convivência social. Infelizmente, a ideologia patriarcal, no sistema protetivo da dignidade sexual, tem funcionado como o Porteiro que, na obra kafkaniana, impedia o acesso à lei, ou seja, à justiça.

Ora, segundo Rui Guerra, em um de seus mais belos poemas, introduzido na letra da mú- 
sica Fado Tropical, que compôs em parceria com Chico Buarque de Holanda, se a mão fica distante do coração, é porque existe uma grande distância entre a intenção é o gesto. Assim, para que as mulheres não continuem acorrentadas ao antigo paradigma patriarcal, e recebam a proteção que o sistema constitucional exige, é preciso aproximar a mão do coração, ou seja, é preciso transformar em ações concretas os dispositivos legais que, no âmbito meramente formal, garantem o exercício da sexualidade como um atributo da dignidade humana. E, para que isso seja possível, é imprescindível romper com os antigos paradigmas.

Por derradeiro, contudo, também é imprescindível lembrar que o sistema penal não tem função promocional, ou seja, não é eficaz para promover o valor da dignidade sexual nem para garantir, de forma isolada, o respeito e a

\section{REFERÊNCIAS}

1. BRASIL. Ministério da Saúde. Aspectos jurídicos do atendimento às vítimas de violência sexual: perguntas e respostas para profissionais de saúde. Brasília: Ministério da Saúde; 2010.

2. Delmanto C, Delmanto R, Delmanto-Jr R, Delmanto FMA, editors. Código penal comentado. São Paulo: Saraiva; 2010.

3. United Nations. Report of the International Conference on Population and Development, Cairo. New York: United Nations. 1994. integridade dos direitos sexuais e reprodutivos. O sistema penal não é o apanágio para todos os males. Acreditar na proteção exclusiva do sistema penal é um grande equívoco. É preciso, antes de qualquer outra coisa, adotar políticas públicas que considerem a dimensão humana, que sejam hábeis para mudar costumes e concepções culturais, que promovam práticas educacionais destinadas a concretizar a igualdade de gêneros e que fortaleçam as mulheres como cidadãs e seres humanos.

Enfim, as mulheres não podem continuar sendo tratadas como Mérope, que, dominada e controlada pelo poder patriarcal, foi violentada pelo poder sexual masculino, invisibilizada em sua condição humana, desprezada como sujeito de direitos e abandonada e esquecida em uma dimensão mítica androcêntrica.

4. United Nations. Report of the Fourth World Conference on Women, Beijing. New York, United Nations. 1995.

5. Drezett J, Junqueira L, Tardelli R, Antonio IP, Macedo Jr. H, Vertamatti MAF, Abreu LC. Influência do exame médico-legal na responsabilização do autor da violência sexual contra adolescentes. Rev Bras Cresc e Desenv Hum 2011; 21(2): 189-197.

6. BRASIL. Ministério da Saúde. Prevenção e tratamento dos agravos resultantes da violência sexual contra mulheres e adolescentes. Norma técnica. $3^{\mathrm{a}}$ ed. atualizada e ampliada. Brasília: Ministério da Saúde; 2010.

\section{Congresso Internacional de Saúde da Criança e do Adolescente Período: de 02 a 05 DE SETEMBRO DE 2011 Local: Centro de Convenções Rebouças Informações: www.congressocdh.com.br cdh.fsp@gmail.com - (11) 7959-0253 / 3061- 7775}

